\title{
DEVELOPMENTS AND BEHAVIORS OF SLIP-RELEASED NOVEL CONNECTORS IN STEEL-CONCRETE COMPOSITE STRUCTURES
}

\author{
Yang Ding ${ }^{1,2}$, Xiao-Meng Dai ${ }^{1}$ and Jia-Bao Yan ${ }^{1,2 *}$ \\ School of civil engineering, Tianjin University, Tianjin 300072, China \\ ${ }^{2}$ Key Laboratory of Coast Civil Structure Safety of Ministry of Education, Tianjin University, Tianjin 300072, China \\ *(Corresponding author: E-mail: ceeyanj@163.com)
}

\section{A B S T RACT}

Effective connection between steel beam and concrete slab is the key issue for steel-concrete composite structures. The slip-released connectors were developed to overcome cracking of the concrete in the hogging moment region of a continuous beam. A full-scale push-out test with two specimens was conducted to investigate the slipping behaviors of the connectors. Test results offered useful information on the slipping behaviors of the connectors in terms of load-slip behaviors and failure modes. FE models were developed for the slip-released connectors and the accuracy of the FE simulation was checked by the reported test results. Two concepts of the connectors, i.e., an improved version with foamed plastic blocks covered by protecting shell and the sliding connectors were developed to improve the structural performances of the slip-released connectors. Numerical simulations results showed that both concepts could effectively release the shear force within their slipping allowed limit and could achieve the performance requirement of releasing slip.

\section{A R T I C L E H I S T O R Y}

$\begin{array}{ll}\text { Received: } & \text { 12 June } 2017 \\ \text { Revised: } & \text { 28 October } 2017 \\ \text { Accepted: } & \text { 17 December } 2017\end{array}$

K E Y W O R D S

Composite structures;

Slip-released connectors;

Push-out test;

Finite element analysis;

Shear resistance

\section{Introduction}

Steel-concrete composite structure became popular in recent several decades since it was initially developed in the 1920s and substantially used in the 1950s. Steel-concrete composite structure usually consists of a concrete slab and an underneath steel beam. The effective connection between steel beam and concrete slab is essential to steel-concrete composite structure since it governs its flexural resistance.

Many types of connectors, e.g., headed stud connectors, have been widely used in the steel-concrete composite structure. Slipping and uplift behaviors of the stud connectors were investigated by researchers, e.g., Spremic et al. [1], Han et al. [2] Lin et al. [3] and Ju [4]. Related connectors were also developed, tested and compared. Chu et al. [5] investigated the shear resistance behaviors of a newly puzzle shape of crestbond rib shear connector by experiments. Chung et al.[6] performed push-out tests with numerous parameters on T-type Perfobond rib shear connector for steel concrete composite bridges. Henderson et al. [7-8] investigated and compared the behaviors of different types of shear connectors by tests and theoretical derivation. Dai et al. [9] focused on the effects of concrete strength and stud collar size on the shear strength of the demountable shear connectors by experimental studies. Yan et al. $[10,11]$ investigated the mechanical behavior of J-hook connectors by push-out tests. He et al. [12] tested the behaviors of the perfobond strip connector by experimental study. All these connectors above restrain the slipping and uplifting displacements between steel and the concrete slab and can be named as slip-restricted connectors [13]. In the sagging moment region of composite beams or girders, the slip-restricted connectors ensure the steel and concrete work compositely to achieve full utilization of the steel and concrete materials. However for continuous composite beams or bridges, tensile stress occurs in the hogging moment region, causing the cracking of concrete slab [14]. Prestressed techniques are usually adopted to solve this cracking problem. However, the stress loss will be high due to the compatible deformation between steel and concrete.

Another way to solve this cracking problem is to release the steelconcrete interfacial slip. The flexible shear (FS) connectors (see Fig. 1) developed by Abe and Hosaka [15] are in $\mathrm{H}$ - or $\mathrm{T}$ - section with web covered by soft foaming polystyrol plate. Since the top flange of the connector is not covered by foaming polystyrol and directly anchored to the concrete, the web of the steel connector will be bent under shear force. Thus, slip between the steel beam and the concrete slab is allowed and the interfacial shear force is partially released. However, the stiffness of the connector's web can not be ignored, and its shear resistance still needs to be accounted. Nie et al. [16] proposed an improved version of the flexible connector namely Uplifted-Restricted and Slip-Permitted (URSP) connector as shown in Fig. 2. The main improvement from the FS to the URSP connector is that the flange of the connector is covered with foamed plastic blocks. Thus the steel-concrete interfacial slip is released through the compressive deformation of the foamed plastic blocks. However, the slipping behaviors of the slip-released connector have not been fully investigated. Improvements and optimizations of this type of connector are still required to improve the slipping behavior of the composite structures.

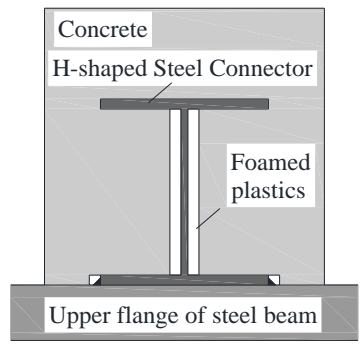

(a) H-section

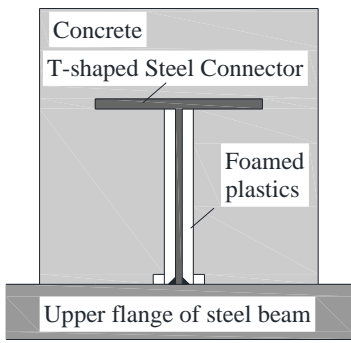

(b) T-section
Fig. 1 FS connector

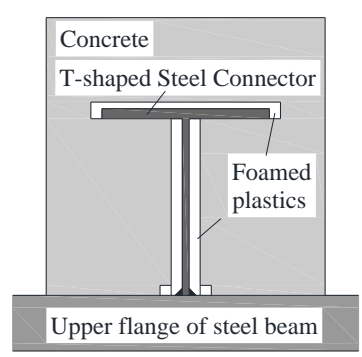

Fig. 2 URSP connector

This paper focused on the slipping behaviors of the slip-released connectors. A full-scale push-out test program consisting of two specimens was reported. Test results offered useful information on the ultimate strength, the shear force-slip curves and failure mode. The experimental results showed that the flange of the $\mathrm{T}$-shaped connector was anchored in the concrete that makes sure the directly transformation of the shear force from the connector to the concrete without deformations in the foamed plastic blocks. A finite element model (FEM) was also developed for USRP connectors using general commercial software ABAQUS. The accuracy of the developed FE model was checked through validations against the reported test results. To fully release the steel-concrete interfacial shear force, two concepts, i.e., an improved version with foamed plastic blocks covered by 
protecting shell and sliding connectors were developed to improve the structural performances of the slip-released connectors. The slipping behaviors of these concepts were studied through numerical simulations.

\section{Full-scale push-out test on ursp connectors}

\subsection{Test specimens}

To investigate the slipping behavior of the slip-released connectors, a fullscale push-out test was carried out. As shown in Fig. 3, the slip-released connector consisted of a T-shaped steel stud and covering Ethylene-Vinyl Acetate (EVA) foamed plastic blocks. The diameters of the shank and the flange were $28 \mathrm{~mm}$ and $130 \mathrm{~mm}$, respectively. The slipping limit of the connector was determined by the thickness of the side foamed plastic blocks under compression, i.e., $40 \mathrm{~mm}$ in this case. Fig. 4 shows the details of the push-out test specimens. Six slip-released connectors were welded on the top surface of steel base with $8 \mathrm{~mm}$ fillet weld. A concrete slab was casted on the top surface of the steel base. The concrete slab measures $1200 \times 110 \times 350 \mathrm{~mm} 3$ in length $\times$ width $\times$ depth and reinforced by $16 \mathrm{~mm}$-diameter steel bars.

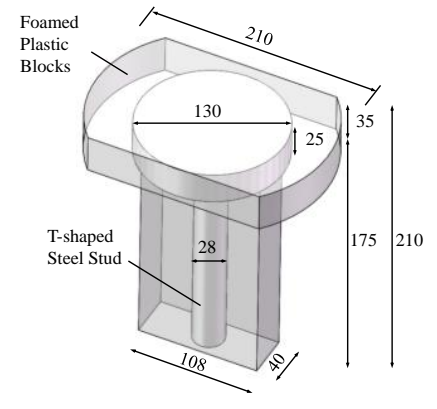

(a) Isometric view

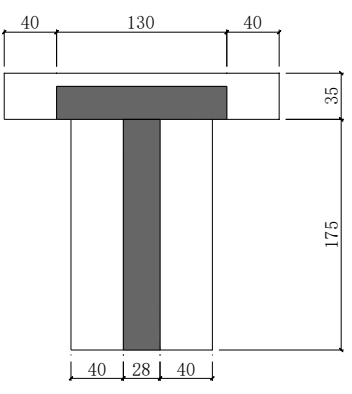

(b) Sectional view

Fig. 3 Slip-released connector (unit: $\mathrm{mm}$ )

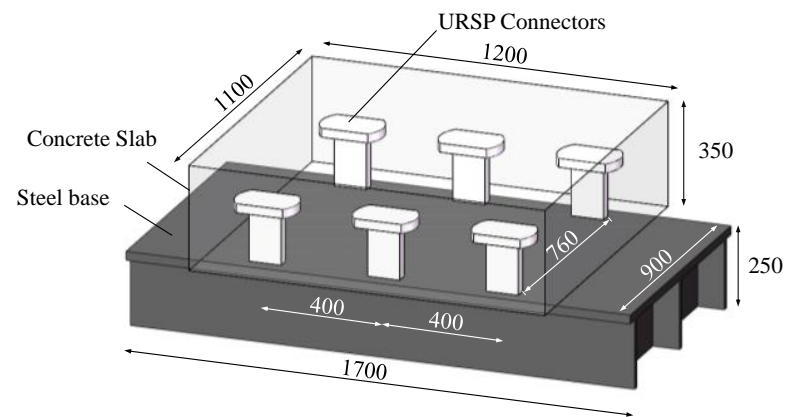

Fig. 4 Specimen of push-out test (unit: $\mathrm{mm}$ )

\subsection{Material properties}

The T-shaped steel studs were fabricated with U20452 (45\#) steel while the steel base was processed with Q235B steel. Tensile test was performed on these steel reinforcements according to Chinese standard GB/T 228.1-2010 [17]. The results are listed in Table 1 and the engineering tensile stress-strain curves of steel are shown in Fig. 5.

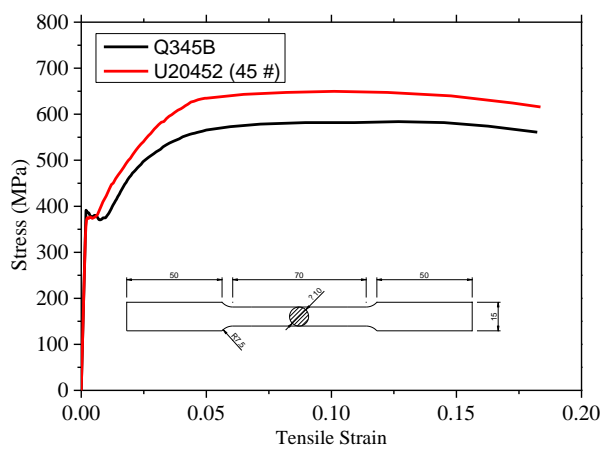

Fig. 5 Engineering tensile stress-strain curves of steel

The concrete slabs adopted C60 normal weight concrete. The mechanical properties of the concrete as listed in Table 2 were obtained through compressive test at 28 days after casting according to Chinese standard GB/T50081-2002 [18]. Three $150 \times 150 \times 150$ cubes (No. 1-3) were prepared for compressive strength test which determined the concrete strength grade. According to Chinese standard, axial compressive strength test must be done before elastic modulus test. Six $150 \times 150 \times 300$ prims (No. 4-9) were prepared for axial compressive strength and elastic modulus tests. Half of the six prims (No. 4-6) were tested for axial compressive strength. The other prisms (No. $7-$ 9) were tested for elastic modulus.

Table 1

Mechanical properties of steel

\begin{tabular}{cccccc}
\hline $\begin{array}{c}\text { Material prop- } \\
\text { erty }\end{array}$ & $\begin{array}{c}\text { Steel } \\
\text { grade }\end{array}$ & $\begin{array}{c}\text { Yield } \\
\text { strength } \\
(\mathrm{MPa})\end{array}$ & $\begin{array}{c}\text { Ultimate } \\
\text { strength } \\
(\mathrm{MPa})\end{array}$ & $\begin{array}{c}\text { Elastic } \\
\text { modulus } \\
(\mathrm{GPa})\end{array}$ & Elongation \\
\hline $\begin{array}{c}\text { T-shaped steel } \\
\text { stud }\end{array}$ & $\begin{array}{c}\mathrm{U} 20452 \\
(45 \#)\end{array}$ & 370.4 & 649.4 & 204.1 & 21.6 \\
$\begin{array}{c}30 \mathrm{~mm} \text { steel } \\
\text { plate }\end{array}$ & $\mathrm{Q} 345 \mathrm{~B}$ & 393.1 & 576.3 & 201.3 & 23.8 \\
\hline
\end{tabular}

Table 2

Mechanical properties of concrete

\begin{tabular}{ccccc}
\hline No & Size $(\mathrm{mm})$ & $\begin{array}{c}\text { Compressive } \\
\text { strength }(\mathrm{MPa})\end{array}$ & $\begin{array}{c}\text { Axial compressive } \\
\text { strength }(\mathrm{MPa})\end{array}$ & $\begin{array}{c}\text { Elastic mod- } \\
\text { ulus }(\mathrm{GPa})\end{array}$ \\
\hline 1 & $150 \times 150 \times 150$ & 67.6 & - & - \\
2 & $150 \times 150 \times 150$ & 62.1 & - & - \\
3 & $150 \times 150 \times 150$ & 63.4 & - & - \\
4 & $150 \times 150 \times 300$ & - & 39.3 & \\
5 & $150 \times 150 \times 300$ & - & 37.8 & \\
6 & $150 \times 150 \times 300$ & - & 39.7 & 36.1 \\
7 & $150 \times 150 \times 300$ & & & 35.5 \\
8 & $150 \times 150 \times 300$ & & & 36.6 \\
9 & $150 \times 150 \times 300$ & & 38.9 & 36.1 \\
Average & - & 64.4 & &
\end{tabular}

\subsection{Test setup and measurements}

Fig. 6 shows the setup for push-out test. The steel base was fixed to the ground by six bolts. To simulate the loads acting on the actual structure, $25 \mathrm{kN}$ vertical load of was applied on the top surface of the concrete slab to simulate the certain pressure $(36.5 \mathrm{kPa})$ on the interface between the steel base and the concrete slab of Haihe Bridge in Tianjin, China [19]. Horizontal displacement controlled type of loading was applied on the side surface of the concrete slab by a hydraulic servo loading system. One specimen was applied by horizontal monotonic load and the other was applied by horizontal cyclic load. Slip between the concrete slab and the steel base was measured by two Linear Variable Differential Transformers (LVDTs).

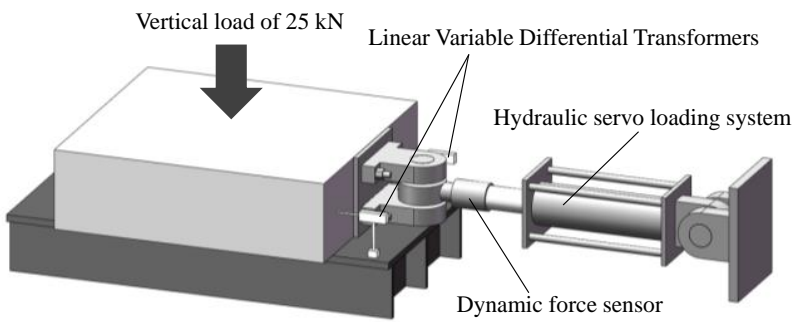

(a) Sketch

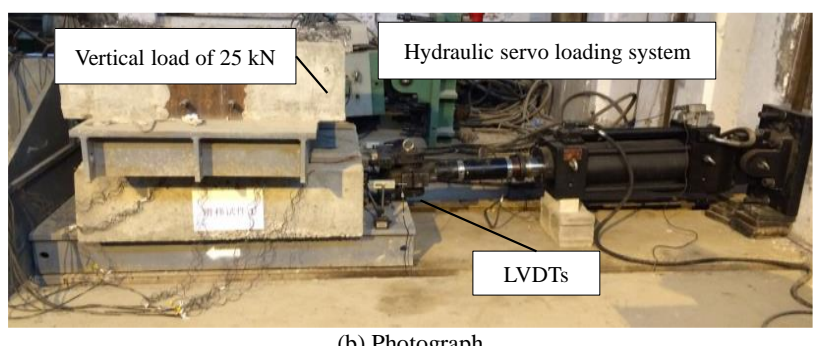

Fig. 6 Test setup

\subsection{Experiments results and discussion}

\subsubsection{General behavior}

Fig. 7(a) and (b) show the shear force-slip curves of the tested two specimens. These curves showed that the shear force-slip curve of the specimen under monotonic load, as shown in Fig. 7 (a), can be divided into four working stages:

(a) At the first stage, i.e., curve OA in Fig. 7(a), the shear force increases 
with micro slip. The interfacial shear force was taken by the steel-concrete interface bonding and static friction; the connectors were not subjected to the shear force. At the end of this stage, i.e., point A in Fig. 7(a), the initial bonding failed and slip between the concrete slab and I-beam occurred. This initial bonding stress usually consists of mechanical, chemical bonding and static friction. Fig. 8(a) shows the slip traces on the top surface of the steel base.

(b) At the second stage, i.e., curve $\mathrm{AB}$ in Fig. 7(a), the interfacial shear force increases almost linearly with the increase of the slip. The connectors were subjected to the shear force and the T-shaped steel studs deformed meanwhile the foamed plastic blocks were compressed. The shear force was taken by the connectors and the interfacial dynamic friction.

(c) At the third stage, i.e., curve BC in Fig. 7(a), the interfacial shear force increases nonlinearly with the increase of the slip and achieved its ultimate resistance at the end of the stage. The T-shaped steel studs deformed further and the weld was in the material hardening stage. At the end of the stage, the weld toes at the root of the T-shaped steel studs failed in shear mode. The sound of metal fracture was heard that accompanied with the failure of the connector.

(d) At the fourth stage, i.e., curve CD in Fig. 7(a), the weld at the root of the T-shaped steel studs failed successively and the interfacial shear force reduces in a steps. At the end of the stage, all the connectors in the specimen failed and the applied shear force was only taken by the friction. Spalling of the concrete took place near the bottom surface of the concrete slab as shown in Fig. $8(b)$.

The shear force-slip curve of the specimen under cyclic load is shown in Fig. 7(b) and the skeleton curve of the specimen under cyclic load is compared with the curve of the specimen under monotonic load in Fig. 7 (a). These two curves exhibit similar behaviors, though the cyclic one decreases more rapidly than the monotonic one because more damage accumulated in the cyclic load.

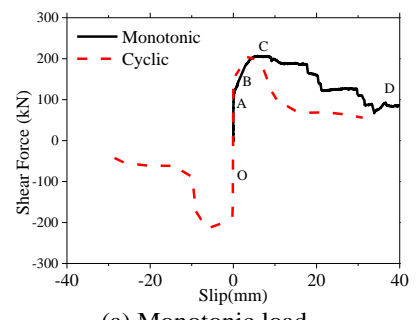

(a) Monotonic load

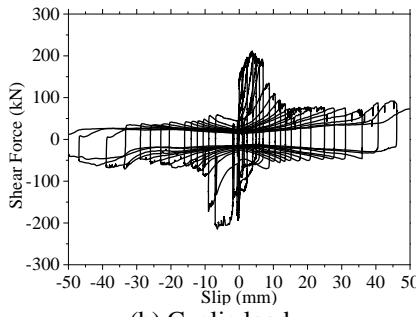

(b) Cyclic load
Fig. 7 Shear force-slip curves derived from push-out test

The main failure mode of the push-out test was the welding toes fracture at the root of the T-shaped steel studs. This type of failure mode usually occurred to the large-diameter stud shear connectors [20, 21]. Fig. 9(a) shows the welding fracture at the weld toe on the top surface of the steel base. As shown in Fig. 9(b), the bottom surface of the concrete slab was scratched by the remains of the fillet weld during the slip process after fracture of the weld, and the scratches were about $5 \mathrm{~mm}$ in depth. The shanks of the connectors were tilted during the push-out test, and a $12 \mathrm{~mm}$-width gap was observed between the shank of the connector and the foamed plastic blocks. The compressive deformation was about $12 \mathrm{~mm}$ while compared with the thickness of the compressive side of the foamed plastic was $40 \mathrm{~mm}$. The side of the plastic foam was only compressed by $30 \%$ before final failure of the specimen.

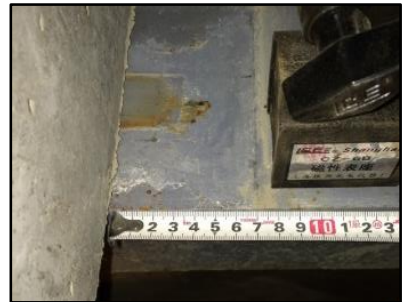

(a) Slip traces

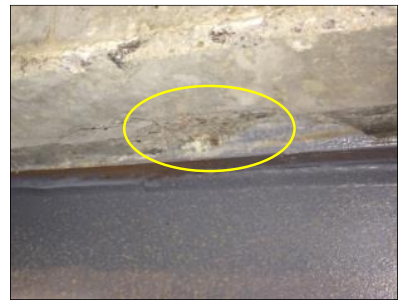

(b) Concrete spalling
Fig. 8 General Behaviors of the test

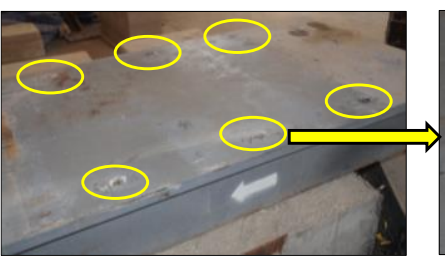

(a) Top surface of the steel base

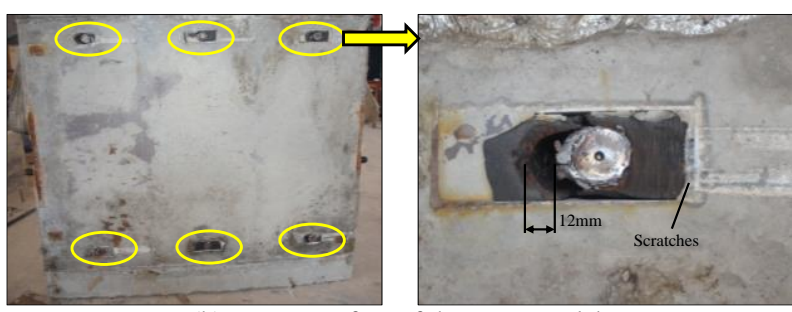

(b) Bottom surface of the concrete slab

Fig. 9 Weld fracture between slip-released connectors and steel base

\subsubsection{Failure mode}

The test results in this paper are compared with existing connectors, including URSP connector [16, 22], welded and demountable stud connectors (result in C30 concrete) [9], blind bolt connector (specimen PBB-RT) [23] and PBL connector (standard PBL specimen) [12]. Fig. 10 shows comparison of the load-slip curves in these tests. The shear forces are normalized as $\mathrm{P} / \mathrm{Pu}$. $\mathrm{Pu}$ is the ultimate strength of a curve. The comparison shows that the initial stiffness of the curve in this paper is greater than that of URSP connector and demountable connector. The Slip/ Ts at ultimate strength in this paper $(0.10)$ is significantly lower than URSP connector $(0.55)$ and the curve decreases more rapidly after the peak. The comparison indicates that the foamed plastic blocks are not significantly compressed. The behavior of the connector is similar to welded stud shear connectors. The connector in this paper can not fully release the slip between the concrete and the steel. Stiffness of the connector is not ignorable. The reason of the unexpected behavior can be conclude: During the casting, the foamed plastic blocks suffered pressure by fresh concrete. Localized deformations were generated at the concrete-foam interfaces as shown in Fig. 11. This greatly reduced the slipping allowance between the concrete and the connector. Thus, the shear force will be directly transferred from the connector to the concrete without deformations in the foamed plastic blocks.

The idealized slip-released connectors should poses low initial shear stiffness and allow slipping. However, from the experimental shear force-slip curves, the structural performances of these connectors are still not satisfactory. Further improvements are still necessary.

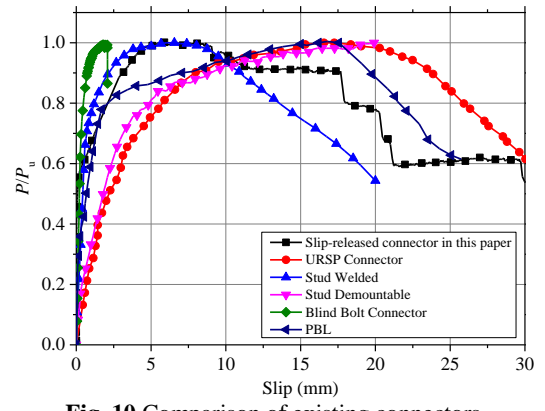

Fig. 10 Comparison of existing connectors

T-shaped Steel

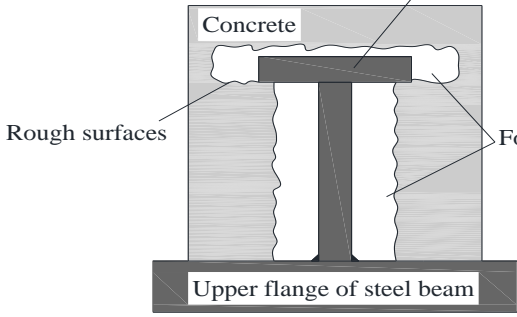

Fig. 11 Rough surfaces generated between the flange and the concrete

\section{Finite element analysis}

3.1. Geometry, elements and mesh size 
A FE model was developed by general finite element program ABAQUS/CAE. Considering the symmetry of the geometry and loading pattern, half of the connector (1/12 of a test specimen) was modeled. The FE model consisted of four parts, i.e., steel plate base, T-shaped steel studs, fillet weld and concrete slab. Considering the elastic modulus and strength of the plastic foam is 3.0 MPa, 0.25 MPa that are much smaller compared with those of steel and concrete, it is thus not modeled in the FEM. To simulate the rough surfaces and the anchored-flange, the interfaces between the bottom surface of the flange of the T-shaped steel stud and the concrete were tied.

The FE model shown in Fig. 12 mainly utilized three-dimensional eight nodes continuum elements in the ABAQUS element library with hourglass control (C3D8R). The C3D8R element is an eight-node linear brick element with reduced integration and three translation degrees of freedom at each node. The concrete slab in vicinity of the connector was modeled by threedimensional ten-node continuum elements (C3D10I) due to its complex shape.

Different mesh sizes were used in the FE model for the balance between accuracy of the analysis and computing processing cost. The concrete mesh sizes in and out the vicinity of connector were $25 \times 25 \times 30 \mathrm{~mm} 3$ and $30 \times 30 \times 30$ $\mathrm{mm} 3$, respectively. The mesh sizes for T-shaped steel stud and fixed steel base were $10 \times 10 \times 10 \mathrm{~mm} 3$ and $40 \times 40 \times 40 \mathrm{~mm} 3$, respectively. The mesh size for the weld toe at the root of the T-shaped steel stud was $2 \times 2 \times 2 \mathrm{~mm} 3$.

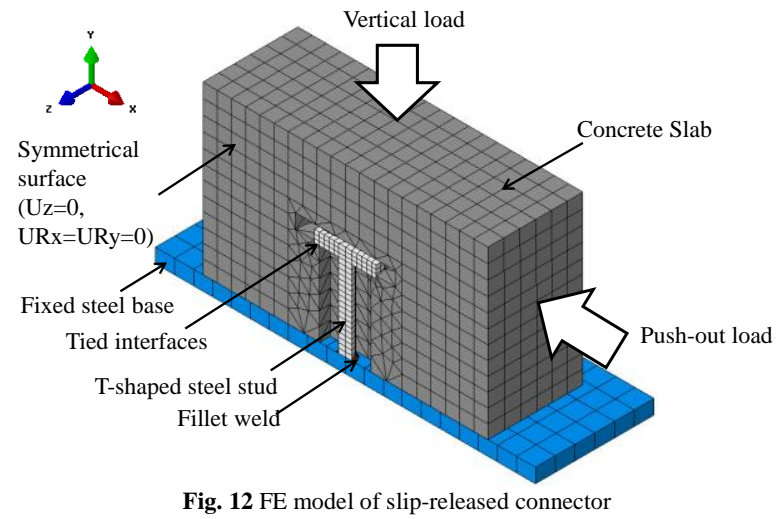

3.2. Material model

The concrete damage plasticity model was used for the concrete slab in the FE model. The strain-stress curves in Chinese code GB50010-2010 [23] were adopted as the input data for the definition of the CDPM model as the following:

$$
\sigma_{c}=\left(1-d_{c}\right) E_{c} \varepsilon
$$

$d_{c}= \begin{cases}1-\frac{\rho_{c} n}{n-1+x^{2}} & x \leq 1 \\ 1-\frac{\rho_{c}}{\alpha_{c}(x-1)^{2}+x} & x>1\end{cases}$

$\rho_{c}=\frac{f_{c k}}{E_{c} \varepsilon_{c k}}$

$n=\frac{E_{c} \varepsilon_{c k}}{E_{c} \varepsilon_{c k}-f_{c k}}$

$x=\frac{\varepsilon}{\varepsilon_{c k}}$

where, $\sigma_{\mathrm{c}}$ is the compressive stress of the concrete, $\varepsilon_{\mathrm{c}}$ is the compressive strain of the concrete, $f_{\mathrm{ck}}$ is the compressive stress of standard concrete cubes, $\varepsilon_{\mathrm{ck}}$ is the strain at $f_{\mathrm{ck}}, d_{\mathrm{c}}$ is the parameter for axial compressive damage evolution of concrete. Tensile stain-stress curve was set similarly as the compressive curves:

$$
\begin{aligned}
& \sigma_{t}=\left(1-d_{t}\right) E_{c} \varepsilon \\
& d_{t}= \begin{cases}1-\rho_{c}\left[1.2-0.2 x^{5}\right] & x \leq 1 \\
1-\frac{\rho_{t}}{\alpha_{t}(x-1)^{1.7}+x} & x>1\end{cases}
\end{aligned}
$$

$$
\begin{aligned}
& \rho_{t}=\frac{f_{t k}}{E_{c} \varepsilon_{t k}} \\
& x=\frac{\varepsilon}{\varepsilon_{t k}}
\end{aligned}
$$

Other plasticity parameters were set including dilation angle of $30^{\circ}$, flow potential eccentricity of 0.1 , ratio of biaxial/uniaxial compressive strength of 1.15 .

The plastic model was used for steel of the connector according to the engineering tensile stress-strain curves of steel in Fig. 5. Plasticity parameters were set, i.e., the yield strengths of $370 \mathrm{MPa}$ (Q345B) and $393 \mathrm{MPa}$ (U20452), the elastic modulus of $206 \mathrm{GPa}$ and the Poisson ratio of 0.3 .

\subsection{Load and boundary condition}

A displacement controlled type of loading was applied on the side surface of the concrete slab as shown in Fig. 12. A constant vertical load was applied on the top surface of the concrete slab to simulate the pressure in the normal direction to the steel-concrete interface.

The T-shaped steel stud was welded connected to the top surface of the steel base by fillet welding. On the bottom surface of the steel base, both translational and rotational freedoms of the nodes were restrained. Considering symmetry of the geometry and loading pattern, translational freedom $\mathrm{Uz}$ and rotational freedoms URx and Ury of the nodes on the symmetrical surface were restrained.

Surface-to-surface contact was used to model the interactions among interfaces of different parts. In the normal direction to the contact surface, the hard contact algorithm was used that could transfer the pressure under compression and allow separation under tension. In the tangent direction to the contact surface, friction algorithm was used to describe the interfacial frictions.

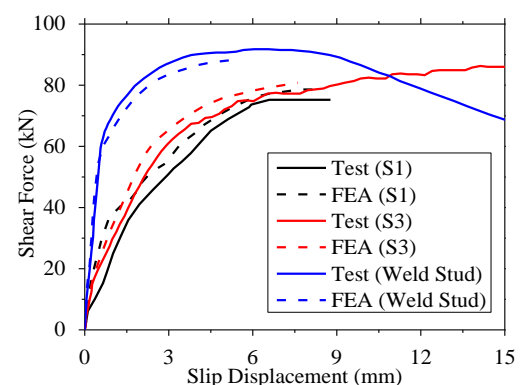

(a) Slip-load curves of studs

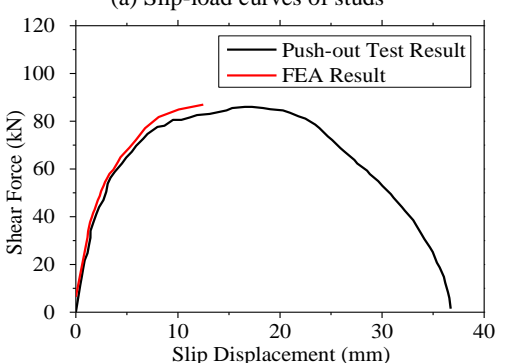

(c) Slip-load curves of URSP connecto

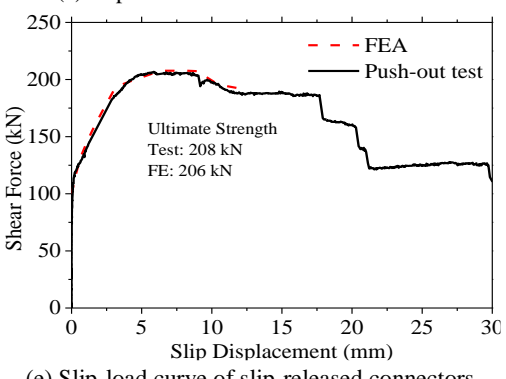

(e) Slip-load curve of slip-released connectors

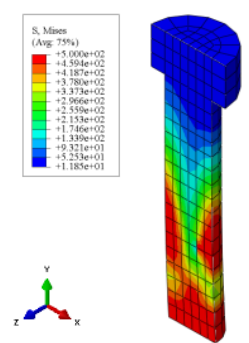

(b) Stress on welded studs

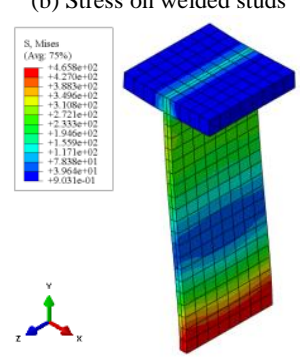

(d) Stress on URSP connector

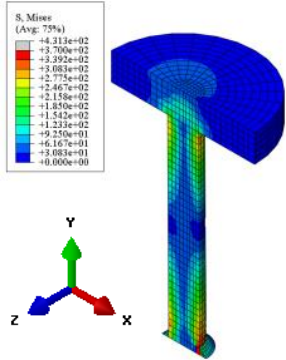

(f) Stress on T-shaped stud
Fig. 13 Validation of FE models

\subsection{Validation}

The accuracy and feasibility of the FE models was verified through comparison the shear force-slip displacement curves and failure modes. For better validation the FE models, four more comparisons with existing push-out tests' results were made along with the slip-released connector's test. The corresponding FE models were developed and the validations were made. The 
geometry and material properties was set according to corresponding references. Fig. 13 (a) and (b) shows the test and predicated curves and Mises stress of three studs, i.e., two types of demountable studs (S1 and S3) and one welded studs in reference [9]. Fig 13 (c) and (d) shows the curves and Mises stress of URSP connector in reference [20]. A good agreement is seen in the comparisons and the effectiveness of the FE models was verified.

The predicted curve of the slip-released connector was compared with test one in Fig. 13 (e). The curves are in good agreement in the first three stages. Mises stress on T-shaped steel stud before failure was shown in Fig. 13 (f), the failure mode of the connector was fracture of the welding toe at the root of the T-shaped steel stud. The FE predicted elastic stiffness and ultimate strength are $23.95 \mathrm{kN} / \mathrm{mm}$ and $208 \mathrm{kN}$ compared with experimental value of $24.13 \mathrm{kN} / \mathrm{mm}$ and $206 \mathrm{kN}$

\section{Development of URSP connectors}

Since the experimental studies showed that the current existing slipreleased connectors could not provide the satisfactory structural performances, two concepts of the slip-released connector were developed that offered alternative forms of slip-released connectors.

\subsection{Concept I: Protecting Shell}

Concept I slip-released connector adopts the Polyvinyl chloride (PVC) shell to cover the connectors. This protecting shell is about 1-2 mm thick that forms a required gap between the stud and the concrete slab as shown in Fig. 14. Due to the enough stiffness of the PVC shell, it could avoid the rough surfaces produced by the pressure of fresh concrete.

\subsection{Concept II: Slidable Connector}

Concept II sliding connector adopts square holes to release the interfacial slip. As shown in Fig. 15, the sliding connector consists of three parts, i.e., an $\mathrm{H}$-shaped steel connector, multiple pairs of bolts and nuts and two foamed plastic blocks. Square holes are set on one side of the $\mathrm{H}$-shaped steel connector and each square hole matches with a set of bolt and nut. The bolts are welded on the upper flange of the steel beam and each bolt is sheathed with a sleeve. The height of the sleeve is $0.5 \mathrm{~mm}$ higher than the thickness of the connector flange plate to avoid over-tightening. The bolts, sleeves and nuts are sealed with the foamed plastic blocks. The lower side of each foamed plastic block is slotted, the bolts and nuts could move smoothly. The foamed plastic blocks protect the bolts and square holes from fluid concrete as seals during the concrete casting. This type of connector allows slip along the square holes and avoids separation of the steel beam from the concrete slab.

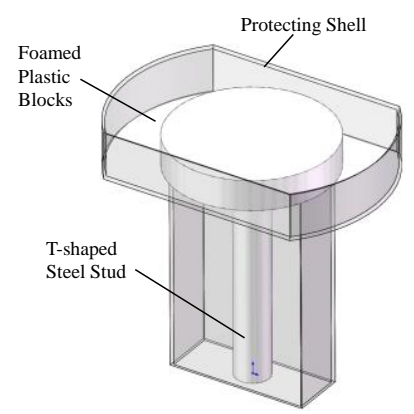

(a) Isometric view

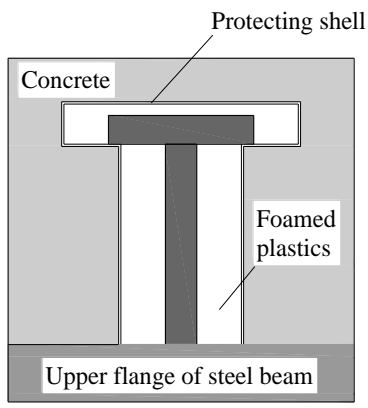

(b) Sectional view
Fig. 14 Concept I: covering the foamed plastic blocks with protecting shell

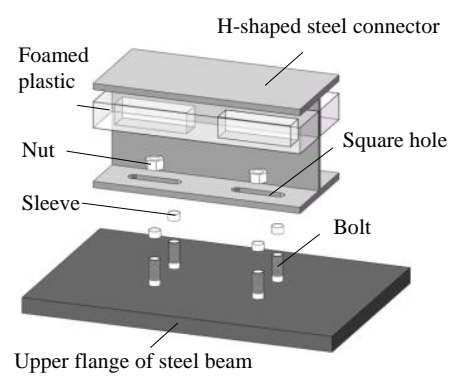

(a) Exploded view

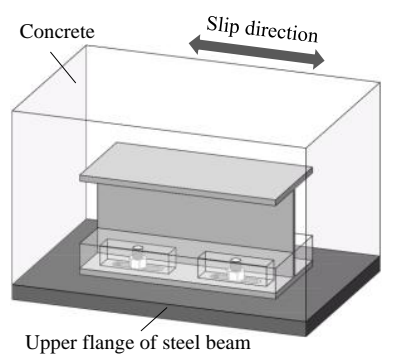

(b) Isometric view
Fig. 15 Concept II: Sliding connector schematic

\subsection{Evaluation of structural performance on the novel connectors by FEA}

In order to investigate the slipping behaviors of these concepts, the FE model developed in section 3 was used. Considering the symmetric geometry and loading pattern, half of the connector was modeled to save computational cost. The boundary and loading conditions were the same as the precious model. A displacement controlled type of loading was applied on the side surface of the concrete slab and a constant vertical load was applied on the top surface of the concrete slab.

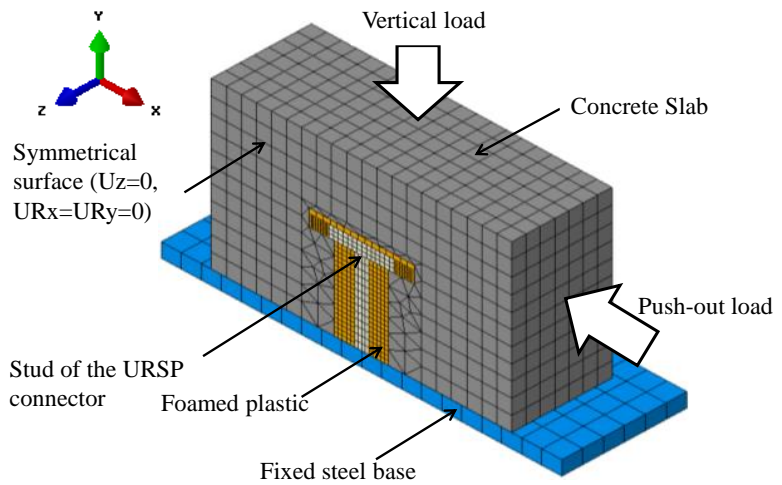

(a) Concept I

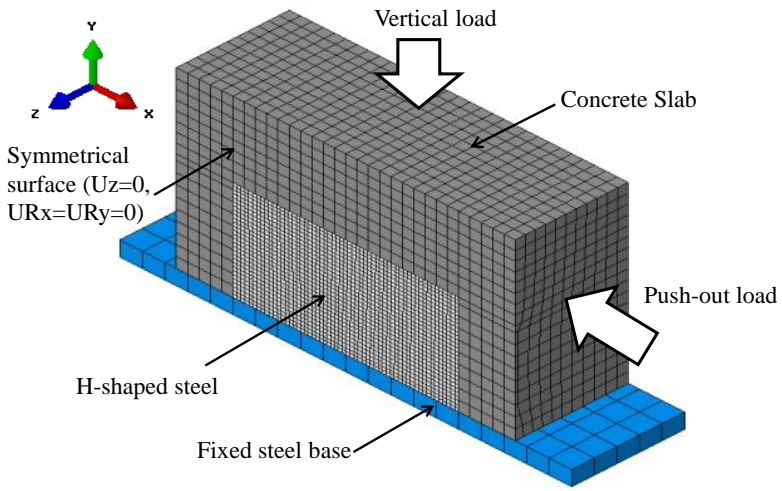

(b) Concept II

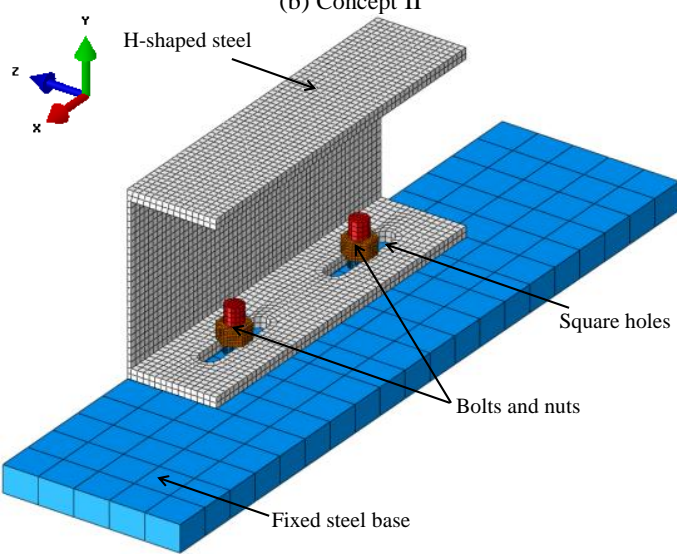

(c) Internal view of Concept II

Fig. 16 FE models of the developed concepts

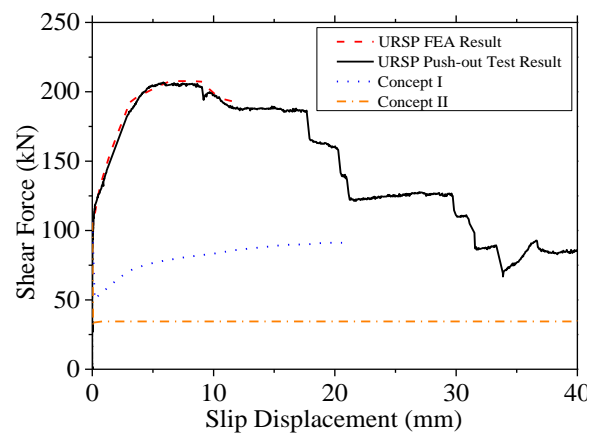

Fig. 17 Comparison of FEA result of Concept I and II 
Fig. 16 (a) shows the FE model for Concept I. Fig. 16 (b) and Fig. 16(c) show the FE model of Concept II. The diameter of the bolts was set as $20 \mathrm{~mm}$; the length of the square hole in this model was set as $80 \mathrm{~mm}$. Thus, the allowed sliding distance on both sides is $40 \mathrm{~mm}$. In this model, the flange of the connector was not anchored and could move smoothly along the square holes. Considering that the interfacial shear force could not be transferred directly between the connector and the concrete, the effects of the foamed plastics could not be ignored. The comparison of the result of these FE models against the experimental result was shown in Fig. 17.
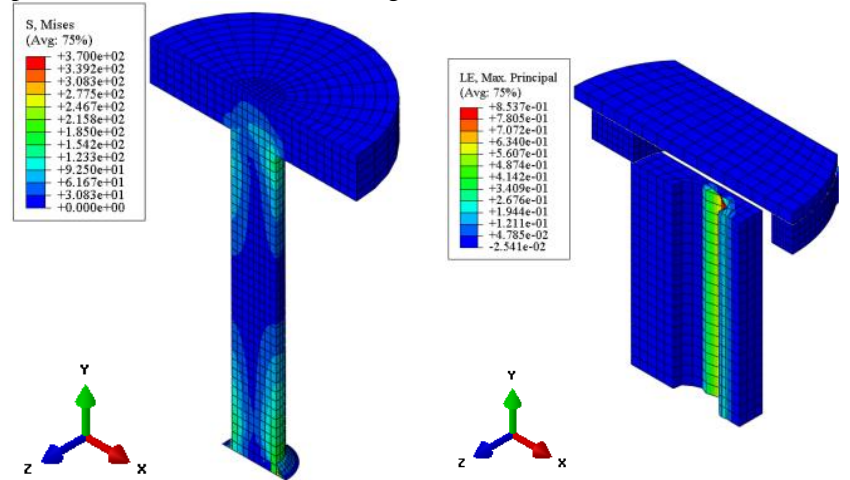

(a) Mises stress on the T-shaped steel stud

(b) Strain on the foamed plastic blocks

Fig. 18 Stress and strain of Concept I before failure

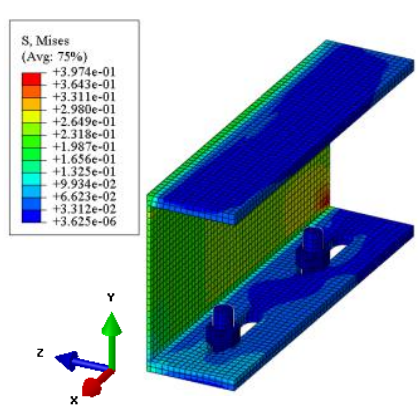

(a) Before slip limit

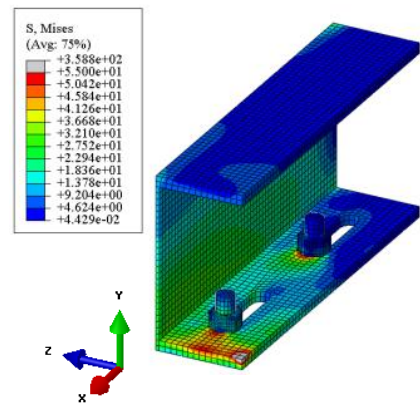

(b) After slip limit
Fig. 19 Mises stress on the H-shaped steel and bolts

\subsection{Evaluation of structural performance on the novel connectors by FEA}

The shear force-slip curves of these developed concepts were significantly different from those of the slip-released connectors. In the shear force-slip curve of Concept I, after the initial bonding failed and the concrete slab started to slide, the shear force decreased rapidly to $50.8 \mathrm{kN}$ and then increased slowly. The failure mode was fracture of the welding toe, as shown in Fig. 18(a). The foamed plastic blocks were significantly compressed by $50 \%$ and the maximum shear force of this FE model was $56 \%$ lower than those of the test and the FEA results at the same slip, as shown in Fig. 18(b). This indicated that the slipping behavior of the slip-released connector could be improved after the protecting shell was added.

In the shear force-slip curve of Concept II, after the initial bonding failed, the concrete slab started to slide, the shear force decreased rapidly to $34.5 \mathrm{kN}$ and maintained at this value which equals the friction force between the steel beam and the concrete. That indicated that the shear force was taken by the friction and connectors were not subjected to the shear force within the slipping limit. Once the slip reached its limit allowance of $40 \mathrm{~mm}$, the shear force was taken by the connector and increased significantly to $180.5 \mathrm{kN}$ (see Fig. 19(b)). Under this boundary condition, the sliding connector performed closely to the bolted connectors.

Thus it can be concluded that these two developed concepts could effectively release the shear force within their slipping allowed limit and could achieve the performance requirement of releasing slip.

\section{Conclusions}

This paper presented a study of the slipping behaviors of slip-released connectors in composite structures by push-out test and finite element analysis. A full-scale push-out test on slip-released connectors was carried out to evaluate their slipping behaviors. Finite element model was developed and the accuracy of the FE simulation was checked by the reported test results. Two concepts of slip-released connectors were developed and the structural performances were studied by numerical simulations. Based on these tests and numerical studies, the following observations and conclusions can be drawn;

- The test results showed the flange of the T-shaped steel stud was anchored in the concrete, the shear force was directly transferred from the connector to the concrete without deformations in the foamed plastic blocks. Localized deformations which greatly reduced the steel-concrete interfacial slipping allowance were generated at the concrete-foam interfaces. The shear resistance of the connector reduced at the slip of $6.0 \mathrm{~mm}$ and the connectors failed successively. The failure mode of the connector fracture of the welding toes at the root of the T-shaped steel studs.

- A FE model was developed for the slip-released connectors and the results was checked by the test results. The numerical simulation result showed that predicted failure mode of the connector was fracture of the welding toe at the root of the T-shaped steel stud, the same as the push-out result. The FE predicted elastic stiffness and maximum resistance are $23.95 \mathrm{kN} / \mathrm{mm}$ and 208 $\mathrm{kN}$ compared with experimental value of $24.13 \mathrm{kN} / \mathrm{mm}$ and $206 \mathrm{kN}$.

- Two concepts of slip-released connectors were developed, i.e., an improved version with foamed plastic blocks covered by protecting shell and a new type of connectors named as sliding connectors. Numerical simulations were carried out and the results showed that both concepts could effectively release the shear force within their slipping allowed limit and could achieve the performance requirement of releasing slip.

This paper only presented limited experimental and numerical studies on slip-released connectors. Further experimental studies and FE simulations are still required to develop the corresponding design guidelines on slip-released connectors.

\section{Acknowledgment}

This study was funded by National Natural Science Foundation of China on a project (grant number 51608358). The authors gratefully express their gratitude for the financial support.

\section{References}

[1] Spremic M., Markovic Z., Veljkovic M., et al., D. "Push-out experiments of headed shear studs in group arrangements", Advanced Steel Construction, 9(2), 139-160, 2013.

[2] Han Q.H., Wang Y.H., Xu J., et al., "Static behavior of stud shear connector in elastic concrete-steel composite beams", Journal of Constructional Steel Research, 113, 115-126, 2015

[3] Lin Z.F., Liu Y.Q. and Roeder C.W., "Behavior of stud connections between concrete slabs and steel girders under bending moment", Engineering Structures, 117, 130-144, 2016

[4] Ju X.C. and Zeng Z.B., "Study on uplift performance of stud connector in steel-concrete composite structures", Steel Composite Structures, 18(5), 1279-1290, 2015.

[5] Chu T.H.V., Bui D.V., Le V.P.N., et al., Ahn, J.H. and Dao, D.K., "Shear resistance behaviors of a newly puzzle shape of crestbond rib shear connector: An experimental study", Steel Composite Structures, 21(5), 1157-1182, 2016.

[6] Chung C.H., Lee J. and Kim J.S., "Shear strength of T-type Perfobond rib shear connectors", KSCE Journal of Civil Engineering, 20(5), 1824-1834, 2016

[7] Henderson I.E.J., Zhu X.Q., Uy B., et al., "Dynamic behavior of steel-concrete composite beams with different types of shear connectors, Part I: Experimental study", Engineering Structures, 103, 198-307, 2015

[8] Henderson I.E.J., Zhu X.Q., Uy B., et al., "Dynamic behavior of steel-concrete composite beams with different types of shear connectors. Part II: Modelling and comparison", Engineering Structures, 103, 308-317, 2015.

[9] Dai X.H., Lam D. and Saveri E., "Effect of concrete strength and stud collar size to shear capacity of demountable shear connectors", Journal of Bridge Engineering, 141(11) 04015025, 2015

[10] Yan J.B., Liew J.Y.R. and Zhang M.H., "Shear-tension interaction strength of J-hook connectors in steel-concrete-steel sandwich structure", Advanced Steel Construction, 11(1), 72-93. 2015

[11] Yan J.B., Liew J.Y.R., Sohel K.M.A., et al., "Push-out tests on J-hook connectors in steelconcrete sandwich structure", Materials and Structures, 47, 1693-1714, 2014.

[12] He S.H., Fang Z., Fang Y.W., et al., "Experimental study on perfobond strip connector in steel concrete joints of hybrid bridges", Journal of Constructional Steel Research, 118, 169-179, 2016.

[13] Zona A. and Ranzi G., "Shear connection slip demand in composite steel-concrete beams with solid slabs", Journal of Constructional Steel Research, 102, 266-281, 2014.

[14] Lin W.W. and Yoda T., "Experimental and numerical study on mechanical behavior of composite girders under hogging moment", Advanced Steel Construction, 9(4), 309-333, 2013.

[15] Abe H. and Hosaka T., "Flexible shear connectors for railway composite girder bridges", Composite Construction in Steel and Concrete IV, ASCE, Reston, VA, 71-80, 2002.

[16] Nie J.G., Lin Y.X., Tao M.X., et al., "Uplift-Restricted and Slip-Permitted T-Shape 
Connectors", ASCE, Journal of Bridge Engineering, 20(4), 04014073, 2015.

[17] GB/T 228.1-2010, Metallic materials-Tensile testing-Part 1: Method of test at room temperature. 2010, General Administration of Quality Supervision, Inspection and Quarantine of the People's Republic of China, Beijing, China.

[18] GB/T50081-2002, Standard for test method of mechanical properties on ordinary concrete, Ministry of Construction of China, Beijing, China, 2002.

[19] Luo G.L., "Numberical Simulation of Haihe Bridge Based on Multi-scale Model", Tianjin University, Tianjin, China, 2015.

[20] Lee P.G., Shim C.S. and Chang S.P. "Static and fatigue behavior of large stud shear connectors for steel-concrete composite bridges", Journal of Constructional Steel Research, 61, 1270-1285, 2005

[21] Shim C.S., Lee P.G. and Yoon T.Y., "Static behavior of large stud shear connectors", Engineering Structures, 26, 1853-1860, 2004

[22] Nie X., "Study on the structural behavior of key components in steel-concrete composite rigid frame bridge", 2013, Tsinghua University, Beijing, China.

[23] Pathirana S.W., Uy B., Mirza O., et al., "Strengthening of existing composite steelconcrete beams utilizing bolted shear connectors and welded studs", Journal of Constructional Steel Research, 114, 417-430, 2015.

[24] GB50010-2010, Code for design of concrete structures, Ministry of Construction of China, Beijing, China, 2010. 